\title{
New Solvent for Polyamide 66 and Its Use for Preparing a Single- Polymer Composite-Coated Fabric
}

\author{
Mostafa Jabbari (DD, Mikael Skrifvars, Dan Åkesson, and Mohammad J. Taherzadeh \\ Swedish Centre for Resource Recovery, University of Borås, Borås, Sweden \\ Correspondence should be addressed to Mostafa Jabbari; mostafa.jabbari@hb.se
}

Received 1 July 2018; Accepted 13 September 2018; Published 17 October 2018

Academic Editor: Andrea Camposeo

Copyright @ 2018 Mostafa Jabbari et al. This is an open access article distributed under the Creative Commons Attribution License, which permits unrestricted use, distribution, and reproduction in any medium, provided the original work is properly cited.

\begin{abstract}
Polyamides (PAs) are one of the most important engineering polymers; however, the difficulty in dissolving them hinders their applications. Formic acid (FA) is the most common solvent for PAs, but it has industrial limitations. In this contribution, we proposed a new solvent system for PAs by replacing a portion of the FA with urea and calcium chloride (FAUCa). Urea imparts the hydrogen bonding and calcium ion from the calcium chloride, as a Lewis acid was added to the system to compensate for the $\mathrm{pH}$ decrease due to the addition of urea. The results showed that the proposed solvent (FAUCa) could readily dissolve PAs, resulting in a less decrease in the mechanical properties during the dissolution. The composite prepared using the FAUCa has almost the same properties as the one prepared using the FA solution. The solution was applied on a polyamide 66 fabric to make an all-polyamide composite-coated fabric, which then was characterized. The FAUCa solution had a higher viscosity than the one prepared using the neat FA solvent, which can be an advantage in the applications which need higher viscosity like preparing the all-polyamide composite-coated fabric. A more viscous solution makes a denser coating which will increase the water /gas tightness. In conclusion, using the FAUCa solvent has two merits: (1) replacement of $40 \%$ of the FA with less harmful and environmentally friendly chemicals and (2) enabling for the preparation of more viscous solutions, which makes a denser coating.
\end{abstract}

\section{Introduction}

Aliphatic polyamides (PAs), also called nylons, are a class of semicrystalline polymers that contain amide groups which are intercalated along linear alkane chains [1]. Solution processing of aliphatic PAs is quite challenging due to the fact that only a few solvents, such as formic acid (FA) and cresol [2] or fluoric solvents [3], can dissolve them. All of the solvents being used for the dissolution of PAs have severe environmental challenges. A few attempts have been made [2] to replace the existing solvents or propose new solvents. Papadopoulou et al. [2] mixed FA with trifluoroacetic acid and acetone. Charlet et al. [4] studied the crystallization and dissolution behavior of polyamide 6-water systems under pressure. Nirmala et al. [5] used FA (85 wt\%), acetic acid, dichloromethane, 1,1,1,3,3,3-hexafluoro-2-propanol, trifluoroacetic acid, and chlorophenol in their study. Basically, dissolving PAs is difficult due to two reasons: (a) polyamides are highly crystalline, whereas the above treatment holds for amorphous polymers, and (b) solvents for polyamides are believed to act by virtue of strong, highly specific polar forces [6].

Polyamide (PA) is a well-known high-performance engineering plastic (technical thermoplastic [7]) with high strength and good fatigue resistance [8] and excellent mechanical and physical properties, which is why it is increasingly used in industrial machinery [7]. Nylon is the common name of linear aliphatic PAs. Nylons are important commercial polymers, with uses ranging from fibers to cooking bags to coatings [9], carpets, upholstery, and apparel [10].

Coated fabrics are flexible composites, consisting of a fabric substrate and a polymeric coating [10]. The coating could be on one side or on both sides, with either the same or different polymeric coating per side [10]. Coated woven fabrics are used in a wide range of structural applications to provide lightweight, architecturally striking solutions [11]. The physical properties of a coated fabric depend on the specific properties of the substrate, coating 
formulation, coating technique, and processing conditions during coating [10]. There are two principal types of coated woven fabric: a glass fiber fabric with a PTFE (polytetrafluoroethylene) coating and a polyester fabric with PVC (polyvinyl chloride) coating [12]. Both PTFEand PVC-coated fabrics are employed today in different types of tents and architectural membrane structures all over the world [13]. As the fabric is prepared from a high-crystalline polymer (spun fiber), it can resist environmental loads, as tensile stresses in the plane of the fabric [12]. These fabrics are popular mainly due to their affordable prices, high strength, durability, resistance to wear and tear, various colors, and soft texture [11]. They are often used for wide-span surfaces, membrane-cable structures, and pneumatic constructions [13]. One recent application of coated fabrics is their application as a textile bioreactor which is a vessel to conduct the biological processes (fermentations) [14]. The PVC-coated fabric was the first material proposed for this purpose. The recent promising candidate was the all-polyamide compositecoated fabric (APCCF) which showed superior properties over the former one [14]. However, using a high amount of formic acid as the solvent is still one industrial challenge for scaling-up the production.

The aim of this paper was to introduce a new solvent based on the replacement of FA with urea, calcium chloride (industrially abundant chemicals), and water to produce an all-polyamide composite-coated fabric from a PA by solvent casting of only one component to have strong adhesion between the coating and the fabric as well as enhanced recyclability.

\section{Material and Methods}

2.1. Materials. The formic acid, urea, and calcium chloride used in this work were supplied by Sigma-Aldrich (ACS reagent grade, $>98 \%)$. The PA66 plain woven fabric (70 grams per square meter (gsm)) was provided by FOV Fabrics $\mathrm{AB}$ (Borås, Sweden). As a polymer source to produce a solution, PA fiber production waste from the weaving process at FOV Fabrics was used.

2.2. Solvent Preparation. The solutions were prepared by adding $35 \mathrm{~g}$ of PA waste scraps into $100 \mathrm{~g}$ solvent mixtures, which, in turn, were obtained by mixing different amounts of formic acid (FA), urea (U), calcium chloride $(\mathrm{Ca})$, and distilled water (W) at room temperature, according to the values tabulated in Table 1 . For the cases that had more urea and calcium chloride, it took a while (1-3 minutes) to get a clear solution.

2.3. Composite Preparation. All-polyamide composites were prepared in the form of a flat laminate on the substrate fabric using an isothermal immersion-precipitation method. The solutions of the PA production waste in the formic acid were made by dissolving $35 \mathrm{~g}$ of PA in $100 \mathrm{~g}$ solvent at room temperature. In low concentrations (less than $\approx 30 \% w / w$ ), PA66 readily dissolves in the formic acid containing the solvent mixture at room temperature, but for higher concentrations,
TABLE 1: Ingredients for the solutions (in some cases, the sum is not $100 \%$ - due to the mathematical rounding of the numbers-the names are only for labeling.)

\begin{tabular}{lcccc}
\hline Sample name (FA-U-Ca-W, \%) & FA (\%) & $\mathrm{U}(\%)$ & $\mathrm{Ca}(\%)$ & $\mathrm{W}(\%)$ \\
\hline $100-0-0-0$ & 100.00 & 0.00 & 0.00 & 0.00 \\
$60-7-20-13$ & 60.00 & 6.67 & 20.00 & 13.33 \\
$64-7-14-14$ & 64.29 & 7.14 & 14.29 & 14.29 \\
$90-0-0-10$ & 90.00 & 0.00 & 0.00 & 10.00 \\
$90-10-0-0$ & 90.00 & 10.00 & 0.00 & 0.00 \\
$82-9-9-0$ & 81.82 & 9.09 & 9.09 & 0.00 \\
$69-8-15-8$ & 69.23 & 7.69 & 15.38 & 7.69 \\
$67-4-30-0$ & 66.67 & 3.70 & 29.63 & 0.00 \\
$82-0-0-18$ & 81.82 & 0.00 & 0.00 & 18.18 \\
$75-8-17-0$ & 75.00 & 8.33 & 16.67 & 0.00 \\
$75-0-0-25$ & 75.00 & 0.00 & 0.00 & 25.00 \\
$55-6-39-0$ & 54.55 & 6.06 & 39.39 & 0.00 \\
$50-8-42-0$ & 50.00 & 8.33 & 41.67 & 0.00 \\
$47-8-39-5$ & 47.37 & 7.89 & 39.47 & 5.26 \\
$56-6-25-13$ & 56.25 & 6.25 & 25.00 & 12.50 \\
$50-6-28-17$ & 50.00 & 5.56 & 27.78 & 16.67 \\
$43-7-36-14$ & 42.86 & 7.14 & 35.71 & 14.29 \\
$38-6-43-13$ & 38.30 & 6.38 & 42.55 & 12.77 \\
$35-6-48-12$ & 34.62 & 5.77 & 48.08 & 11.54 \\
\hline & & & &
\end{tabular}

the solution should be agitated for a longer time. In order to assure the completion of dissolution and have the same agitation condition for all the solutions, the sealed solution flasks were put in a shaker at a speed of $100 \mathrm{rpm}$ for 20 hours at $55^{\circ} \mathrm{C}$ to obtain a homogeneous solution [11]. The solutions were cooled to room temperature, and after centrifugation for 10 minutes at a speed of $16,000 \times g$ (meaning 16,000 times Earth's gravitational force) to remove the bubbles, the dopes were cast on a PA fabric with a size of $18 \times 24 \mathrm{~cm}$ fixed on a glass with adhesive tape, using a ZUA 2000 universal film applicator (Zehntner GmbH Testing Instruments, Sissach, Switzerland) with a gap of $175 \mu \mathrm{m}$. Once the casting process was done, after waiting 30 seconds, the glass plate (carrying the fabric and a layer of the PA solution on top of it) was immersed in a distilled water coagulation bath $(10 \mathrm{~L})$ at room temperature to induce polymer precipitation (phase separation). After one hour of coagulation (in the water bath), the composites obtained were first washed three times with distilled water and then held under light press between two sheets of filter papers and dried at $55^{\circ} \mathrm{C}$ in a vacuum oven $(\approx 0.1$ bar $)$ for 2 hours. The samples were kept in a vacuum zipper storage bag for further analysis. The composites were named according to their corresponding solution ingredients (Table 1). The thickness of the composites varied between 150 and $200 \mu \mathrm{m}$. The reason of variation in the thickness could be the strength of the solvent. In other words, if the solvent is stronger, it will dissolve the surface of the fabric in a greater extent which leads to a more reduction of the composite thickness. The thickness of the fabric was $100 \mu \mathrm{m}$ initially. 
2.4. Characterization Methods. The tensile strength properties were evaluated in accordance with the standard method ISO 527 [15]. Dumbbell-shaped test bodies, $75 \mathrm{~mm}$ long (with a width of $4 \mathrm{~mm}$ ), were tested on an MTS 20/M tensile strength tester (MTS Systems Corporation, Eden Prairie, MN, USA), fitted with a $5 \mathrm{kN}$ load cell and a special grip for films, using a crosshead speed of $5 \mathrm{~mm} / \mathrm{min}$. The gauge length, the preload force, and the first approach speed were $33 \mathrm{~mm}, 0.5 \mathrm{~N}$, and $2 \mathrm{~mm} / \mathrm{min}$, respectively. The thickness of the composites was measured using an Elastocon thickness meter (Elastocon, Sweden). A minimum of five test bodies was tested for each material. The specimens were all cut along the warp direction of the fabric.

To investigate the viscoelastic properties of the composites, dynamic mechanical thermal analysis (DMA Q800, TA Instruments, Waters LLC, USA) was performed on the prepared composites. The specimens were run with a film tension clamp using the temperature ramp procedure with a sample dimension of approximately $15 \times 9 \mathrm{~mm}$. The temperature ranged from room temperature to $180^{\circ} \mathrm{C}$ with a heating rate of $3^{\circ} \mathrm{C} / \mathrm{min}$; the frequency and the amplitude were $2 \mathrm{~Hz}$ and $15 \%$ elongation at max, respectively.

Scanning electron microscopy (SEM) was used to monitor the fracture surface morphology of the cross sections of the composites and to check the adhesion between the coating (the PA film) and the fabric. The specimens were obtained by quenching in liquid nitrogen and breaking by hand. As the samples contained fabric, using only quenching in liquid nitrogen did not take apart the sample completely; therefore, after breaking, the unbroken parts were cut by a sharp blade. The studied surface was sputtered with a layer of gold before the measurements. SEM analysis was performed using AIS2100 (Seron Technology, Korea) operated at an acceleration voltage of $18 \mathrm{kV}$.

The viscosity measurements were carried out with a Brookfield viscometer (MA, USA) at $40^{\circ} \mathrm{C}$. The tests were done within 30 seconds for each sample.

Thermogravimetric analysis (TGA) was performed on the composites using the Q500 machine (TA Instruments, MA, USA). About $8 \mathrm{mg}$ of the material was heated from room temperature to $700^{\circ} \mathrm{C}$ at a heating rate of $10^{\circ} \mathrm{C} / \mathrm{min}$ in a nitrogen purge stream.

The $\mathrm{pH}$ measurements were carried out using a Jenway $3505 \mathrm{pH}$ meter (Staffordshire, UK) at room temperature. The $\mathrm{pH}$ sensor was placed in the samples for 30 seconds while being stirred at $200 \mathrm{rpm}$ to reach to an equilibrium.

\section{Results and Discussion}

The most common solvent for polyamides is formic acid (FA), which is neither safe nor easy to handle. To replace a portion of the FA to make it more appropriate, more economical, and safer to handle solvent mixtures, different amounts of urea, calcium chloride, and water were mixed and added to the FA. Thereafter, the polymer was added to the solvent mixtures to make homogeneous solutions. The solutions were used to make all-polyamide compositecoated fabrics by means of a universal film applicator and consecutive coagulation in a water bath as a nonsolvent in order to induce phase separation (phase inversion). As a result, a composite composed of a thin continuous PA layer (the coating) and a PA fabric out of the most common type of aliphatic PA (PA66) was obtained. The hypothesis in this work was that since each urea molecule contains four hydrogens and can establish strong intermolecular interactions ( $\mathrm{H}$-bonding) with the amide groups in the PA, it can disrupt the intermolecular interactions (hydrogen bonding) among the polymer chains, therefore resulting in an easier dissolution. In general, the dissolution of semicrystalline polymers such as polyamide comprises several steps including solvent penetration [16], decrystallization of crystalline domains, amorphous polymer swelling, and chain untangling [17]. Formic acid (as the main solvent) has enough penetration power to penetrate into the PA chains [18]. However, the main goal in this paper was to replace a portion of the FA, meaning that the replacement molecule needed to have enough interactions with the PA chains to start the penetration. As discussed earlier, urea has four hydrogen bonding per unit of molecule, and even if all the four hydrogen cannot engage in hydrogen bonding, urea still has high capability of hydrogen bonding interactions. On the other hand, PA chains contain amide groups which are the strong hydrogen bonding donor/acceptor groups [19], while FA has only one hydrogen bonding per unit of molecule. Therefore, the mixture of FA/urea will have a higher tendency to penetrate into the PA chains. The other steps of dissolution (decrystallization of crystalline domains, amorphous polymer swelling, and chain untangling) would be done faster and easier if the first step (solvent penetration) occurs faster/easier [20,21]. This process will be enhanced by using calcium chloride as a Lewis acid (to nullify the increased $\mathrm{pH}$ due to the addition of urea-an organic base) as well as localizing the paired electrons on the amide groups of PA chains. Different properties were analyzed, and the process parameters were optimized. The selection of different percentages of the solvent's components (FA, urea, calcium chloride, and water) was done by trying to keep the percentage of the FA as low as possible. Water was added to the solvent mixture, both for imparting hydrogen bonding [22] and also for its wellknown effect on the dissolution of polyamides $[4,23]$ when it is used in lower percentages.

3.1. Mechanical Properties. The maximum force divided by the cross-sectional surface area of the samples needed to break the composite in the tensile strength mode; also, the elongation at max of the composites is shown in Figure 1. The thickness of the composites varied between 150 and $200 \mu \mathrm{m}$.

The results from the tensile strength testing (Figure 1) implied an irregular trend. However, a slight trend is evident in terms of the FA content. Four composites had the tensile strength values higher than the one obtained from a solvent out of pure FA. It could be related to the fact that FA partially decomposes the PA chains during the dissolution process [11]. In other composites, which have an FA content that is even less than the FA content of those four good composites, 


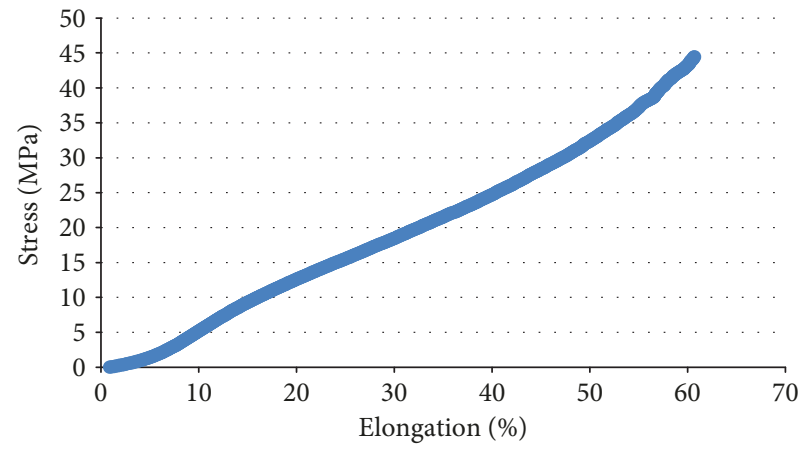

(a)

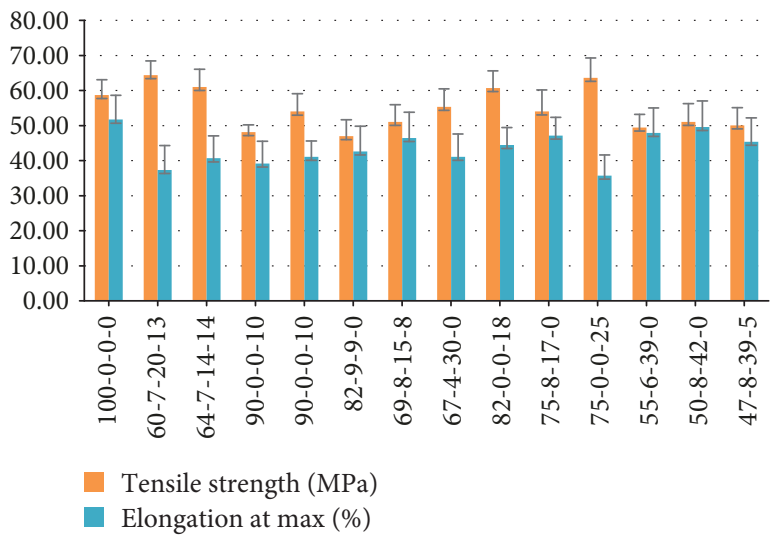

(b)

FIGURE 1: An exemplary stress-elongation at max curve for the sample 60-7-20-13 (a), and the tensile strength and the elongation at max values for the composites (b).

the tensile strength values are not higher than those of the composite 100-0-0-0 (with pure FA). Although it might seem contradictory with the above proposal for increasing the tensile strength value, it could be the effect of the urea/calcium chloride content (and even water content) on the crystallization of the PA chains in the phase inversion process. Regarding the elongation at max, all the composites prepared from the new proposed solvent mixtures in this work have lower values compared to the 100-0-0-0 composite. This might be related to the effect of the localization of the paired electron on the amide groups of PA chains, which plays a role like a spacer [24] during the phase inversion process. We can conclude that the optimized FA content for dissolving PA with the least possible decomposition/degradation is $60 \%$ (the sample 60-7-20-13).

3.2. Viscoelastic Properties. The loss modulus is a measure of energy dissipation. In the region of the glass transition, molecular segmental motions are activated; however, motions occur with difficulty, described as the molecular friction that dissipates much of the force. Therefore, though the material is less stiff, more force is dissipated as heat, increasing the loss modulus. However, after that region, as the chains are free to move (at the temperature higher than the glass transition temperature), much less energy is stored since the molecules can move with the force, resulting in a rapid decline in the storage modulus. As evident in Figure 2, in the sample prepared from pure FA, the maximum in the curve of the loss modulus decreases with the reduction in the amount of FA in the solution. The solvent 60-7-20-13 contains water, and there might be some water molecules left. As the water molecules can act as a plasticizer for polyamide [25], it could plasticise the polymer. More so, it might be related to the effect of higher density of hydrogen bonding on a urea-containing solvent (in 60-7-20-13) as well as the localization of the paired electrons of the amide groups from the PA chains. One of the main characteristics of PAs is the strong interchain interaction that arises from the hydrogen bonding between the amide groups on adjacent chains
[26]. In other words, in the solvation process, the amide groups from the PA chains meet a higher density of hydrogen bonding (offering by urea), leading to weaker intrainteractions among the PA chains, which, in return, decreases the interaction among them. Therefore, they have much more freedom to move in the solvent. This freedom increases the Brownian motion of the chains, which increases their distances from each other [27]. Finally, when they are about to change their phase from solution to solid (coagulation process in the coagulant), they come together in a relatively less-packed structure. Moreover, when they are less-packed in the solid form (having lower crystallinity), their $\mathrm{Tg}$ is slightly lower (Figure 2 for tan delta), and the peak of the loss modulus is seen at a lower temperature for a solution with a higher amount of urea. This proposed reason is intensified with the presence of calcium ion as a Lewis acid in a different way. Calcium ion has free orbital to localize the paired electrons of the nitrogen from the amide group of the PA chains; hence, the hydrogen bonding ability of the amide groups of the PA chains also decreases, and finally the same effect happens. The same trend is seen in the storage modulus as well as in the tan delta.

3.3. Viscosity. The viscosity values are different for various solutions (Figure 3). However, in all solutions, the viscosity value is higher than the one for the solution using only formic acid as a solvent (100-0-0-0). Regarding the merit of the increase in viscosity, during the process of making the APCCF, it was observed several times that when the viscosity of the solution is low, the formed film (coating) does not have enough coherency. It makes sense as it might be due to the less aggregation of polymer chains on top of the fabric and also letting the solution go through more into the fabric which is not favorable. Because, for the application of making the APCCF, only the surface of the fabric must be dissolved partially, not the whole fabric which will decrease the whole tensile strength of the composite, a solution which has higher viscosity is more favorable for making APCCF as it makes a well-formed coating on top of the PA fabric. When 

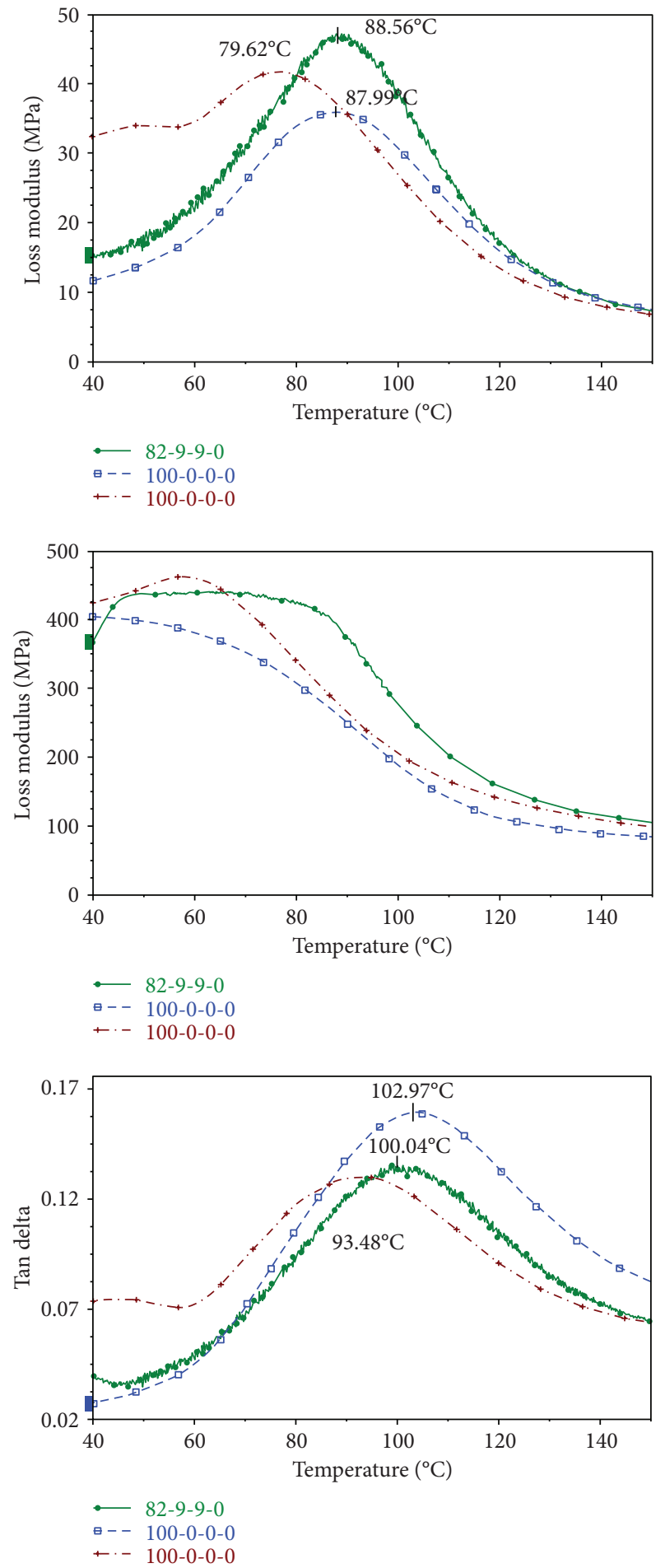

FIgURE 2: Loss modulus, storage modulus, and tan delta for the composites prepared from the new solvents.

the viscosity of the solution is low, the formed film does not have enough coherency. Comparatively, when the same percentage of PA solutions in different solvents gives a different viscosity and, on the other hand, the viscosity of around $4000 \mathrm{cP}$ (for the solution 100-0-0-0) is enough to make a proper coating, the solution 75-8-17-0 (which has the highest

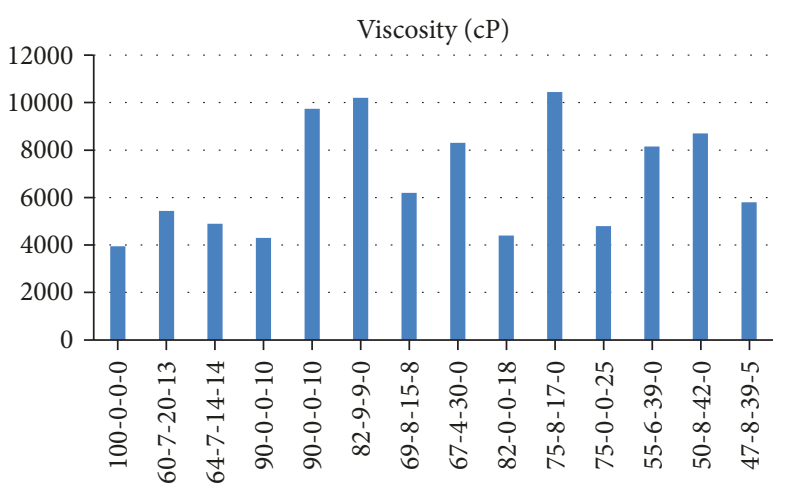

Figure 3: The viscosity values for the composites. The solution made from the solvent mixture $75-8-17-0$ is the most viscous solution due to the intermolecular interactions between the ingredients of the solvent mixture and the polymer.

viscosity value, around $10,500 \mathrm{cP}$ ) will use less polymer. Additionally, as the APCCF must be waterproof and be as gas tight as possible, the coating being formed from a higher viscosity solution will be denser and will increase the APCCF's gas tightness.

The reason for the difference in the viscosity values in different solutions could be related to the difference in the intermolecular interactions between the solvent's molecules and the PA's molecules. The ones that have a higher amount of urea have higher values in viscosity. This is due to the fact that urea can establish hydrogen bonding in large numbers (up to four units) from two sides, which can make a bridge between two PA chains (two bonds from the one side and two bonds from the other side). By establishing these four bidirectional hydrogen bonds, the fluidity of the PA solution decreases, which, in turn, increases the viscosity.

3.4. Morphological Properties. According to the scanning electron microscopic images of the cross section (Figure 4), in almost all the APCCF specimens, there is an excellent adhesion between the coating (formed film) and the fabric. In other words, the boundaries between the fiber of the fabric and the coating are not clear because they have faded due to the adhesion of the two components.

It is obvious that a large part of the cross-sectional area of the fabric is dissolved, and the polymer chains are interdiffused with each other, enabling the APCCF to have a good adhesion between the coating and the fabric, both of which are made out of PA. Although higher surface dissolution helps to create a better adhesion between the fabric and the coating, it also disintegrates the fabric structure and changes the fabric, from being a fibrous form to an amorphous film. Fibers are spun and pose a high crystallinity and thus a good strength while the films are amorphous as they do not have enough time to rearrange their chains in a nice ordered way (fast coagulation in water). Therefore, converting PA from a highly crystalline form to a less crystalline (highly amorphous) form is not favorable from a mechanical point of view. The amount of the surface dissolution should be as low as possible to impart a good adhesion between the fabric 

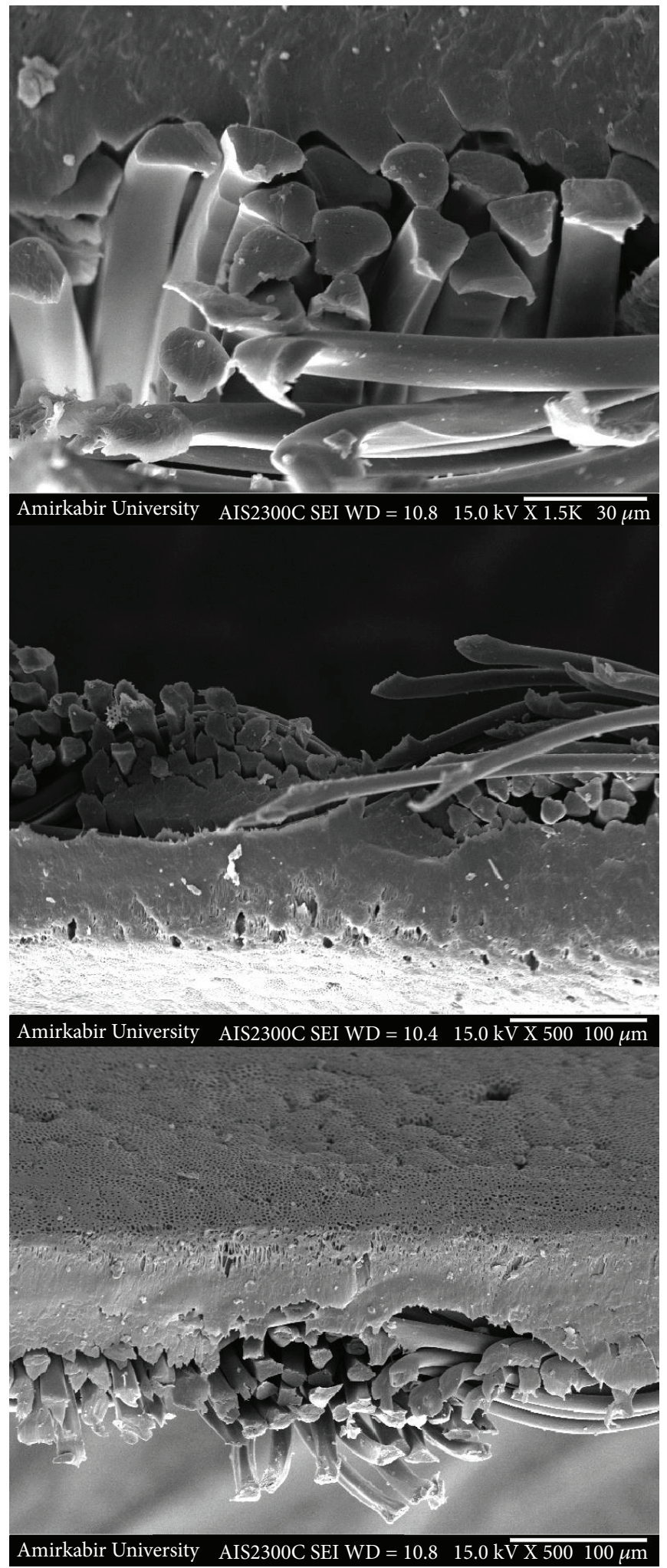

FIGURE 4: Selected cross-sectional SEM micrographs of the composite 60-7-20-13. Strong adhesion is seen between the coating (the top film) and the fibers from the fabric. The fibrils of the fiber closer to the coating are fused to each other.

and the coating, but a higher dissolution is not favorable [11]. Using this new solvent helps the fabric's surface to be partially dissolved more quickly, due to the higher hydrogen bond intensity (due to the presence of urea); hence, the adhesion between the fabric and the coating - the coating (formed film) on top of the fabric-would be stronger. 


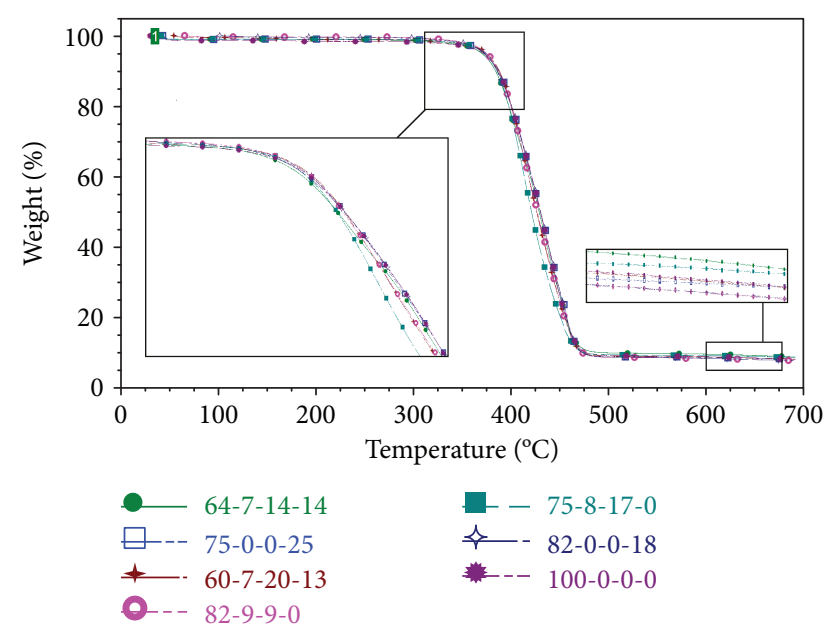

FIGURE 5: TGA curves of the composites prepared via the new solvent.

3.5. Thermogravimetric Analysis (TGA). The TGA curves showed almost the same values and shape (Figure 5). The only composite that deviates more from the rest is the 75-8$18-0$, which tends to decompose slightly earlier than the others, though the difference is not significant. However, it has higher residue percentage compared to the rest of the composites (except the 64-7-14-14). Although PA66 is partially crystalline, all good solvents penetrate the crystallites, disrupting them completely [6]. Calcium ion (which is the acidic ion) is smaller than the urea molecule, resulting in an easier entrance to the crystallites. The final swollen gel is thus amorphous, even though the initial polymer is crystalline [6]. In the composite 75-8-17-0, the ratio of urea to calcium chloride (the source of calcium ion) is 0.5 (Table 2) and the ratio of U/FA is 0.11 . These ratios are the same as those of the composites 69-8-15-8 and 64-7-14-14; however, their Ca/ $(F A+U+W)$ and $U /(F A+C a+W)$ are different. From the last two ratios and the TGA curves, it could be concluded that out of the four ingredients of the new solvent mixture (U, FA, $\mathrm{Ca}$, and $\mathrm{W}$ ), the ratio of $\mathrm{U}$ and $\mathrm{Ca}$ to the other ingredients should be kept as low as possible to have the least disruption of PA crystallites in order not to sacrifice the thermal stability. It is noteworthy that the composite 82-9-9-0, which has the same $\mathrm{Ca} /(\mathrm{FA}+\mathrm{U}+\mathrm{W})$ and $\mathrm{U} /(\mathrm{FA}+\mathrm{Ca}+\mathrm{W})$ ratios (equal to 10), has the lowest residue in the TGA curve, meaning that the closer the two ratios, the less the thermal stability of the composite.

3.6. $\mathrm{pH}$ Values and Observations. From the $\mathrm{pH}$ measurements, it is obvious and reasonable that the solutions that have a higher amount of FA have lower $\mathrm{pH}$. The amine group $(-\mathrm{NH} 2)$ in urea can accept a hydrogen ion, making it a basic substance. However, the carbonyl group $(-\mathrm{C}=\mathrm{O})$ offers a significant opportunity for resonance, which will stabilise the amine group, meaning that the paired electrons on $\mathrm{N}$ is in resonance. This means that urea is very slightly basic (and very close to neutral). However, in the presence of an acid, the basicity of urea increases (as there is plenty of $\mathrm{H}+$ in the solution and the $-\mathrm{NH} 2$ is converted to $-\mathrm{NH} 3+)$. Hence, in the solution, urea is a base, so the reason for adding calcium chloride (which acts as a Lewis base) was to decrease the $\mathrm{pH}$ to make the solution as similar as possible to the pure FA solution. The highest $\mathrm{pH}$ is attributed to the solution $75-0-0-25$ in which $25 \%$ of the water has increased the $\mathrm{pH}$ from -1.74 to -0.30 . Basically, polyamides are polymers with a relatively high density of hydrogen bonds [1]. As PA is a weak acid, a solvent with acidic properties can protonate the amide group; consequently, the amide group will have less possibility to establish hydrogen bonding with other chains. Therefore, it will be easier for the solvent to swell into the polymer and dissolve it. In the first six solutions of the solutions tabulated in Table 2, it was observed that the solution 90-0-0-10 was excellent in terms of homogeneity and dissolution power. This might be related to the lower $\mathrm{pH}$ they have compared to the others, which have higher $\mathrm{pH}$. However, the $\mathrm{pH}$ by itself is not a good criterion to judge the dissolution power of these solutions. For example, in the solution 35-6-48-12, which has a $\mathrm{pH}$ value very close to the $\mathrm{pH}$ of $\mathrm{FA}(-1.66$ vs. -1.74$)$, the observation showed that the solution does not have a high power of dissolution. This might be related to the calcium chloride content $\left(100^{*} \mathrm{Ca} /(\mathrm{FA}\right.$ + urea $+\mathrm{W})$ ), which is $92.59 \%$, while the value is less than $25 \%$ in those showing "excellent" dissolution. The reason for this might be due to the effect of the counterion, chloride. Chloride is a relatively big ion. In lower numbers, they can help the dissolution; however, when they are increased, they most probably promote some interferences with the interactions of other ingredients (FA, urea, and water) with polyamide chains. Therefore, it could be concluded that the calcium chloride content should be less than $25 \%$.

\section{Conclusions}

The preparation of all-polyamide composite-coated fabric (APCCF), a specific form of single-polymer composites, made through a phase inversion method using a new solvent is described. The solvent was obtained by replacing $40 \%$ of the FA with less harmful, cost-effective, more environmentally friendly, safer-to-handle, and industrially available chemicals: urea, calcium chloride, and water. The APCCF prepared in this work using the new solvent mixture does not have inferior properties over the one prepared through FA, such as mechanical and thermal properties. The prepared composite has a strong adhesion between the two constituents due to the use of the same polymer (PA66) in the constituents. The composite is fully recyclable since it contains no other materials except PA, which can be melted or dissolved and reused as a PA source. The prepared composite has a broad range of semistructural applications for providing lightweight, architecturally striking solutions as well as wide-span surfaces, membrane-cable structures, hanging roofs, pneumatic constructions, water-/gas-proof fabric reactors, temporary houses and tents, facade coverings, container linings, and tarpaulins and as material of construction of textile bioreactors. 
TABLE 2: Values for the $\mathrm{pH}$ and the relative components and also the observations.

\begin{tabular}{|c|c|c|c|c|c|c|}
\hline Sample name & $\mathrm{pH}$ & $\mathrm{U} / \mathrm{Ca}$ & $\mathrm{U} / \mathrm{FA}$ & $100^{*} \mathrm{U} /(\mathrm{FA}+\mathrm{Ca}+\mathrm{W})$ & $100^{*} \mathrm{Ca} /(\mathrm{FA}+\mathrm{U}+\mathrm{W})$ & Observation $^{*}$ \\
\hline $100-0-0-0$ & -1.74 & - & 0.00 & 0.00 & 0.00 & Excellent \\
\hline $60-7-20-13$ & -0.74 & 0.33 & 0.11 & 7.14 & 25.00 & Excellent+ \\
\hline $64-7-14-14$ & -0.54 & 0.50 & 0.11 & 7.69 & 16.67 & Excellent \\
\hline $90-0-0-10$ & -1.10 & - & 0.00 & 0.00 & 0.00 & Excellent \\
\hline $90-10-0-0$ & -0.18 & - & 0.11 & 11.11 & 0.00 & Excellent \\
\hline $82-9-9-0$ & -0.75 & 1.00 & 0.11 & 10.00 & 10.00 & Excellent \\
\hline $69-8-15-8$ & -0.74 & 0.50 & 0.11 & 8.33 & 18.18 & Good \\
\hline $67-4-30-0$ & -1.64 & 0.13 & 0.06 & 3.85 & 42.11 & Good \\
\hline $82-0-0-18$ & -0.56 & - & 0.00 & 0.00 & 0.00 & Good \\
\hline $75-8-17-0$ & -0.95 & 0.50 & 0.11 & 9.09 & 20.00 & Good \\
\hline $75-0-0-25$ & -0.30 & - & 0.00 & 0.00 & 0.00 & Fairly good \\
\hline $55-6-39-0$ & -1.69 & 0.15 & 0.11 & 6.45 & 65.00 & Fairly poor \\
\hline $50-8-42-0$ & -1.61 & 0.20 & 0.17 & 9.09 & 71.43 & Fairly poor \\
\hline $47-8-39-5$ & -1.50 & 0.20 & 0.17 & 8.57 & 65.22 & Fairly poor \\
\hline $56-6-25-13$ & -0.91 & 0.25 & 0.11 & 6.67 & 33.33 & Poor \\
\hline $50-6-28-17$ & -0.90 & 0.20 & 0.11 & 5.88 & 38.46 & Poor \\
\hline $43-7-36-14$ & -1.08 & 0.20 & 0.17 & 7.69 & 55.56 & $\mathrm{Bad}$ \\
\hline $38-6-43-13$ & -1.42 & 0.15 & 0.17 & 6.82 & 74.07 & $\mathrm{Bad}$ \\
\hline $35-6-48-12$ & -1.66 & 0.12 & 0.17 & 6.12 & 92.59 & $\mathrm{Bad}$ \\
\hline
\end{tabular}

${ }^{*}$ The markings were assigned based on the homogeneity of the solutions and the uniformity of the cast film on the glass.

\section{Data Availability}

The data used to support the findings of this study are available from the corresponding author upon request.

\section{Conflicts of Interest}

The authors declare that they have no conflicts of interest.

\section{Acknowledgments}

The authors are grateful to FOV Fabrics $A B$ (Sweden) for providing the PA fabric and PA residue and Prof. Dr. Parviz Rashidi Ranjbar for his help.

\section{References}

[1] M. Laurati, A. Arbe, A. Rios de Anda, L. A. Fillot, and P. Sotta, "Effect of polar solvents on the crystalline phase of polyamides," Polymer, vol. 55, no. 12, pp. 2867-2881, 2014.

[2] E. L. Papadopoulou, F. Pignatelli, S. Marras et al., "Nylon 6, 6/ graphene nanoplatelet composite films obtained from a new solvent," RSC Advances, vol. 6, no. 8, pp. 6823-6831, 2016.

[3] K. Behler, M. Havel, and Y. Gogotsi, "New solvent for polyamides and its application to the electrospinning of polyamides 11 and 12," Polymer, vol. 48, no. 22, pp. 6617-6621, 2007.

[4] K. Charlet, V. Mathot, and J. Devaux, "Crystallization and dissolution behaviour of polyamide 6-water systems under pressure," Polymer International, vol. 60, no. 1, pp. 119-125, 2011.

[5] R. Nirmala, H. R. Panth, C. Yi et al., "Effect of solvents on high aspect ratio polyamide- 6 nanofibers via electrospinning," Macromolecular Research, vol. 18, no. 8, pp. 759-765, 2010.
[6] L. Valentine, "Interaction of polyamides with solvents. I. A preliminary survey of the swelling of crosslinked nylon 66 in various types of solvents," Journal of Polymer Science, vol. 23, no. 103 , pp. 297-314, 1957.

[7] G. Vasile, C. Fetecau, and A. Serban, "Experimental research on the roughness of surfaces processed through milling polyamide composites," Materiale Plastice, vol. 51, pp. 205-212, 2014.

[8] Y. Gong and G. Yang, "Manufacturing and physical properties of all-polyamide composites," Journal of Materials Science, vol. 44, no. 17, pp. 4639-4644, 2009.

[9] C. G. Johnson and L. J. Mathias, "In synthesis and solid state NMR of 15n-labeled nylon 12," in 1989 Boston, Massachusetts Meeting of ACS, pp. 523-524, Boston, MA, USA, 1990.

[10] A. K. Sen, Coated Textiles: Principles and Applications, CRC Press, Boca Raton, FL, USA, 2nd edition, 2007.

[11] M. Jabbari, M. Skrifvars, D. Åkesson, and M. J. Taherzadeh, "Introducing all-polyamide composite coated fabrics: a method to produce fully recyclable single-polymer composite coated fabrics," Journal of Applied Polymer Science, vol. 133, no. 7, 2016.

[12] B. N. Bridgens and P. D. Gosling, "Direct stress-strain representation for coated woven fabrics," Computers \& Structures, vol. 82, no. 23-26, pp. 1913-1927, 2004.

[13] A. Ambroziak and P. Kłosowski, "Mechanical properties for preliminary design of structures made from PVC coated fabric," Construction and Building Materials, vol. 50, pp. 74-81, 2014.

[14] M. Jabbari, O. Osadolor, R. Nair, and M. Taherzadeh, "Allpolyamide composite coated-fabric as an alternative material of construction for textile-bioreactors (TBRs)," Energies, vol. 10, no. 11, p. 1928, 2017. 
[15] M. Jabbari, D. Åkesson, M. Skrifvars, and M. J. Taherzadeh, "Novel lightweight and highly thermally insulative silica aerogel-doped poly (vinyl chloride)-coated fabric composite," Journal of Reinforced Plastics and Composites, vol. 34, no. 19, pp. 1581-1592, 2015.

[16] B. A. Miller-Chou and J. L. Koenig, "A review of polymer dissolution," Progress in Polymer Science, vol. 28, no. 8, pp. 12231270, 2003.

[17] M. Ghasemi, M. Tsianou, and P. Alexandridis, "Dissolution of semicrystalline polymers: solvent-induced decrystallization and chain untangling," in 2015 AIChE Annual Meeting, p. 29, Salt Lake City, UT,USA, 2015.

[18] K. V. S. N. Raju and M. Yaseen, "Influence of nonsolvents on dissolution characteristics of nylon-6," Journal of Applied Polymer Science, vol. 43, no. 8, pp. 1533-1538, 1991.

[19] E. Vinken, A. E. Terry, O. van Asselen, A. B. Spoelstra, R. Graf, and S. Rastogi, "Role of superheated water in the dissolution and perturbation of hydrogen bonding in the crystalline lattice of polyamide 4, 6," Langmuir, vol. 24, no. 12, pp. 6313-6326, 2008.

[20] C. H. R. M. Wilsens, Y. S. Deshmukh, B. A. J. Noordover, and S. Rastogi, "Influence of the 2, 5-furandicarboxamide moiety on hydrogen bonding in aliphatic-aromatic poly (ester amide)s," Macromolecules, vol. 47, no. 18, pp. 6196-6206, 2014.

[21] A. N. Derbyshire, E. D. Harvey, and D. Parr, "Solvent-assisted dyeing of nylon 6.6 and polyester fibres," Journal of the Society of Dyers and Colourists, vol. 91, no. 4, pp. 106-111, 1975.

[22] M. G. M. Wevers, V. B. F. Mathot, T. F. J. Pijpers, B. Goderis, and G. Groeninckx, "Full dissolution and crystallization of polyamide 6 and polyamide 4.6 in water and ethanol," in Lecture Notes in Physics, G. Reiter and G. R. Strobl, Eds., vol. 714, pp. 151-168, 2007.

[23] M. Pegoraro, A. Penati, M. Zocchi, and G. Albertini, "Influence of nylon- 6 film solvent treatments on water and water solutions permeability," Annali di Chimica, vol. 74, pp. 589605, 1984.

[24] Z. L. Wang, J. L. Xu, L. J. Wu et al., "Dissolution, hydrolysis and crystallization behavior of polyamide 6 in superheated water," Chinese Journal of Polymer Science, vol. 33, no. 9, pp. 1334-1343, 2015.

[25] P. Y. Le Gac, M. Arhant, M. Le Gall, and P. Davies, "Yield stress changes induced by water in polyamide 6: characterization and modeling," Polymer Degradation and Stability, vol. 137, pp. 272-280, 2017.

[26] Q. Zhou, J. Zhang, J. Fang, and W. Li, “The influence of nanofillers migration on the mechanical property of pa 6/chitosan nanocomposites," RSC Advances, vol. 5, no. 22, pp. 1663116639, 2015.

[27] S.-i. Manabe and R. Fujioka, "Solvent concentration in a specified region of regenerated cellulose solid evaluated from dynamic viscoelasticity in a hydrophilic solvent," Carbohydrate Polymers, vol. 41, no. 1, pp. 75-82, 2000. 


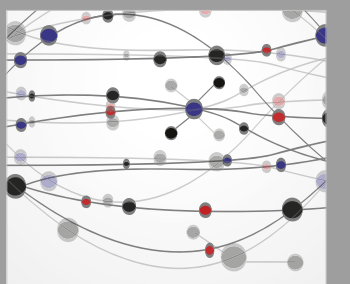

The Scientific World Journal
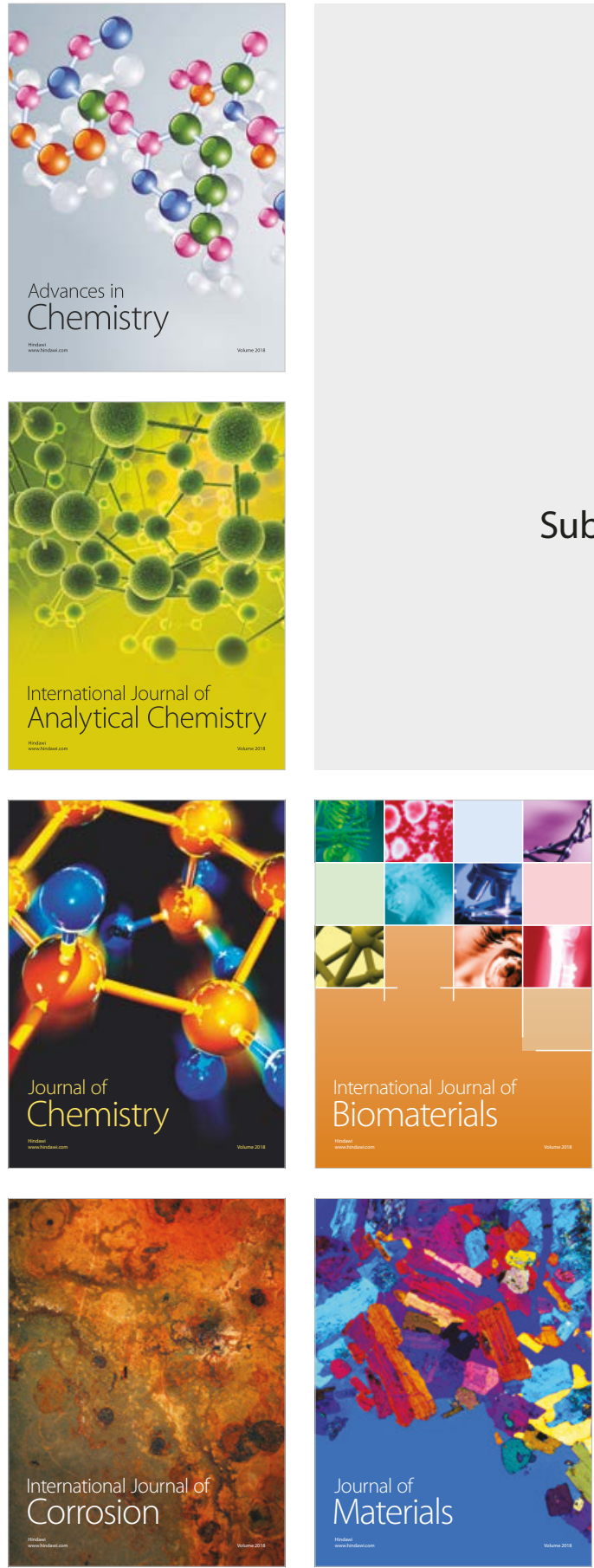

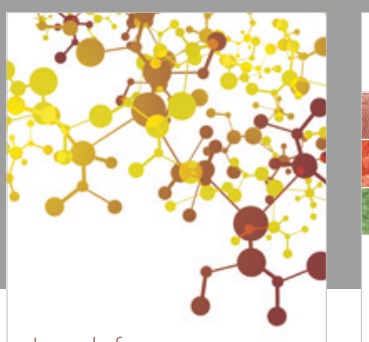

Journal of

Applied Chemistry
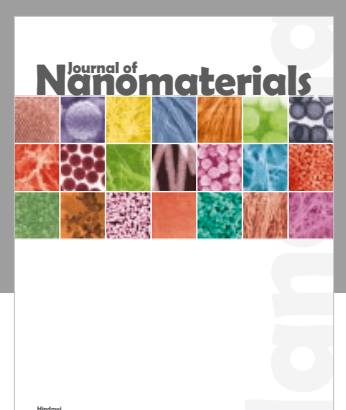

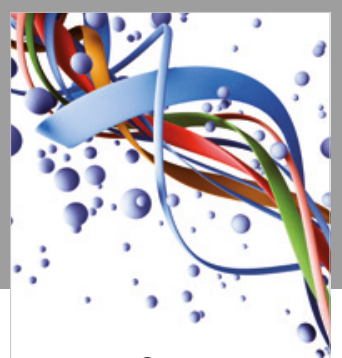

Scientifica

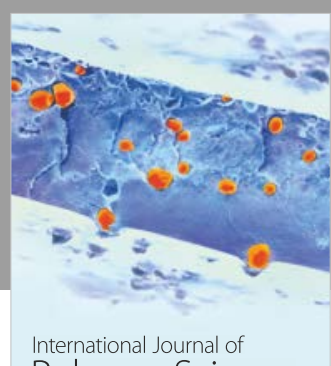

Polymer Science

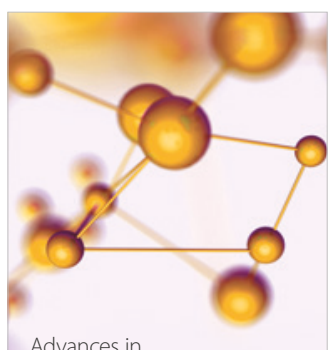

Physical Chemistry
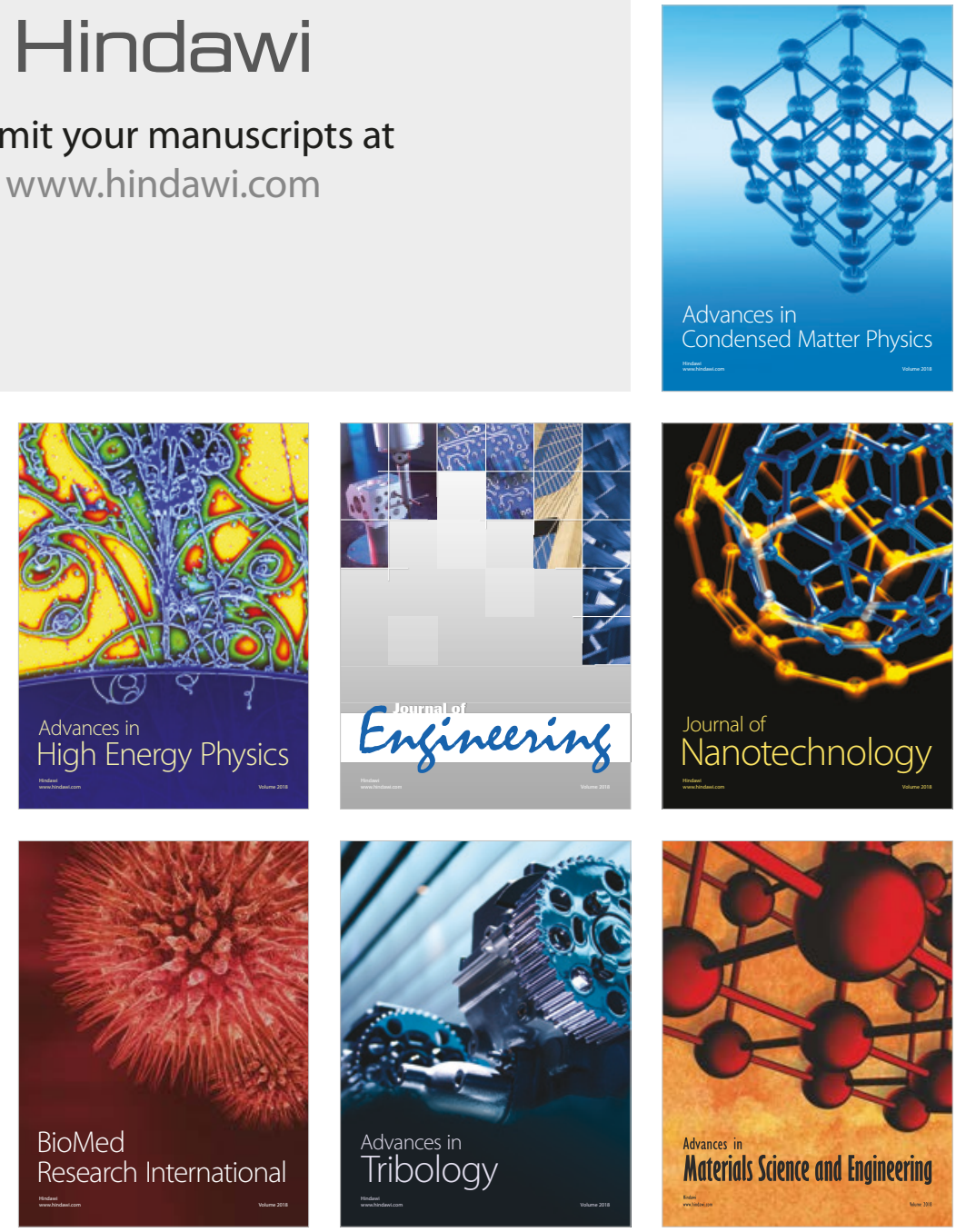